\title{
Segregation of the bulk blend fertilizers
}

\author{
O. Miserque ${ }^{\mathrm{a}, *}$, E. Pirard ${ }^{\mathrm{b}}$ \\ a Agricultural Research Centre, Agricultural Engineering Department, Belgium 146, Chaussée de Namur-5030 Gembloux, Belgium \\ ${ }^{\mathrm{b}}$ Geomac Department, University of Liège, Liège, Belgium
}

Received 1 August 2003; received in revised form 10 March 2004; accepted 19 March 2004

Available online 24 June 2004

\begin{abstract}
Bulk blend fertilizers are a mixture of different kinds of fertilizers in order to obtain a predicted $\mathrm{N}-\mathrm{P}-\mathrm{K}$ chemical composition. Although this production method has some advantages, segregation appears at different stages, from the production to the final spreading on the field.

An experiment has been implemented to predict and quantify the influence of some physical properties on the occurrence of segregation. The principle was to blend two fertilizers having identical physical properties except for one, such as size, shape or density and to measure the segregation of the blend following various operations, such as filling or emptying a container.

Results show that the spread of the fragment size distribution has a big influence on the segregation of the generated heap. In order to reduce this phenomenon, the granulometric spread index (GSI) $\left[\left(d_{84}-d_{16}\right) / 2 d_{50}\right]$ must be smaller than 10 . Other properties don't seem to have an influence. The granulometric segregation can lead to a chemical heterogeneity. The absolute sum of the difference between $d_{16}$ and $d_{84}$ must be limited around $0.5 \mathrm{~mm}$. Above this value, the chemical segregation begins to be excessive. It seems also that if there is a limited difference in size for the components, the chemical segregation is amplified if the density of the fertilizer with the biggest particles is lower. It is not the case for the difference in shape.
\end{abstract}

(C) 2004 Elsevier B.V. All rights reserved.

Keywords: Bulk blend; Fertilizers; Segregation; Flowing

\section{Introduction}

Bulk blends are the result of the physical mixture of different fertilizers between them. With some raw materials containing different nutritive substances, it is possible to obtain a new compound fertilizer better adapted to the requirements of a plant. This process is economical and offers great flexibility. In general, the raw materials used for the bulk blends are solid granulates.

In spite of these advantages, bulk blends also pose segregation problems [1]. Segregation takes place during handling, which consist of loading or unloading flows. This segregation process takes place for each mixture, and it is amplified when components present very different physical properties.

The aim of this work is to analyse the influence of the physical characteristics of the particle on their behaviour during the handling operations involving flows. This is done

\footnotetext{
* Corresponding author. Tel.: +32-81-627140; fax: +32-81-615847.

E-mail address: miserque@cra.wallonie.be (O. Miserque).
}

by creating mixtures with given chemical composition and well-known physical properties. On the basis of these results, it will be possible to propose quality standards for the fertilizers used in bulk blends in order to minimize negative segregation effects.

\section{Materials and methods}

The principle of the experiment is to select two identical fertilizers showing a difference only for size, density or shape. An accurate and precise splitting process provided $10 \mathrm{~kg}$ samples necessary to determine the physical properties.

Then, the prepared $400 \mathrm{~kg}$ mixture is used to simulate routine handling similar to those usually performed with bulk blends. Samples are taken to quantify physical and/or chemical segregation.

\subsection{Flows}

The flow is analysed according to two tests simulating real handling to which fertilizers are subjected. 
The first stage consists of filling a container. This one appears as a rectangular box. At the end of the filling, two samples are taken:

- one is made of three increments selected from the central part of the heap

- the other is made of two increments (i.e., left and right sides) at about $10 \mathrm{~cm}$ from the wall of the container.

A probe was designed to take samples with a minimum of disturbances. It consists of two concentric tubes equipped with a longitudinal slit from approximately $1 \mathrm{~m}$ length and $2.5 \mathrm{~cm}$ across. It is possible to introduce the probe in the heap with the two slits positioned in such a way that nothing can enter the probe. By rotating the inner cylinder it is possible to open the probe and extract one increment. The probe is then closed again and carefully extracted from the heap.

The second stage consists of emptying this container by a trap door, and sampling within the flow is performed in order to follow the evolution of the product. Each sample is the result of about 20 implements collected by a bucket with an opening of $2 \mathrm{~cm}$ width in accordance with EN 1482 [2]. Three samples of an individual weight of approximately 3 $\mathrm{kg}$ are taken, each one representing a third of the mixture.

In case of the samples emptied from the container, the proportion of each component is calculated on the known basis of the chemical composition of the raw materials and the samples.

\subsection{Physical characteristics}

It is possible to find references in the literature of a great number of physical characteristics for granular materials. We only consider the characteristics we wish to study, size, shape and density.

\subsubsection{Size}

A size distribution analysis of the tested materials is performed. For the realization of this measurement, it is referred to the standard EN 1235 [3]. The equipment has seven sieves with square mesh of dimension 1.40, 2.00, $2.50,3.15,3.55,4.00$ and $4.50 \mathrm{~mm}$. The mass of each collected fraction is measured.

In practice, the curve is characterized by various values of percentiles $d_{x}$ (x being the weight fraction passing the sieve of mesh $d$ ). The most commonly used are $d_{10}, d_{16}, d_{50}$, $d_{84}$ and $d_{90}$.

The size distribution range is characterized by the granulometric spread index (GSI) calculated with the following formula:

$\mathrm{GSI}=\frac{d_{84}-d_{16}}{2 \times d_{50}} \times 100$

Other granulometric measurement techniques exist. One of them is the determination by image analysis. This method has the advantage of combining the measurements of size and shape.

\subsubsection{Shape}

The particles of fertilizer can have a spherical shape or a more irregular shape. The shape of the particles is determined by visual inspection which takes into account the shape of the two-dimensional shade of the particles. A systematic approach provides from the measurements a series of independent parameters [4]. We use in particular the measurements of elongation, roughness and of roundness.

The elongation is the relationship between the small and the large axes of the particle. This is obtained by the calculation of the principal moments of inertia.

The measured roughness of the particles is an indication of their smoothness.

Roundness is relevant to characterize these asperities. A value of $100 \%$ characterizes a perfect disc and will decrease when it moves away from this shape.

The imagery was carried out by ombroscopy. To accomplish this, fertilizer particles dispersed on glass were placed in front of a diffuse source of light. The selected enlargement generated a digital representation of about 3500 pixels for a particle $2.5 \mathrm{~mm}$ in diameter which allows a good estimate of its morphometric properties. The binarisation of the image is carried out with a fixed threshold since the conditions of lighting are stable. The minimum number of particles measured by batch is 2000 , which makes it possible to sufficiently minimize the confidence interval around the average of the granulometric and morphometric distributions.

Before proceeding with any measurement, particles with a surface equivalent of less than 100 pixels (i.e., less than $0.4 \mathrm{~mm}$ diameter) and those intercepting the outer edge of the image are automatically eliminated. This elimination is of no consequence since the percentage of grains smaller than $1.4 \mathrm{~mm}$ is generally less than $1 \%$.

The measurement of the static angle of repose is another method to obtain indications about the shape of particles. The static angle of repose is the natural angle that forms a heap of any granular material after flowing freely. The standard of measurement selected is the European standard EN 12047 [5]. Equipment consists of a funnel placed above a plane and square plate. Four shifted diameters of $45^{\circ}$ are traced while passing by the centre of the plate. The funnel is filled with a fertilizer which flows on the plate. The fertilizer forms a heap. The average of the four diameters gives the angle of repose by the formula:

$\alpha=\arctan \left(\frac{2 h}{\bar{d}-d_{1}}\right)$

where

- $h$ is the height of the heap in $\mathrm{mm}(=120 \mathrm{~mm})$,

- $\bar{d}$ is the arithmetic mean of the four diameters measured in $\mathrm{mm}$, 
- $d_{1}$ is the internal diameter of the output of the funnel (25 mm).

Correlations were searched between the various measured properties of shape [6].

\subsubsection{Density}

The fertilizer can present a bulk density ranking between 750 and $1300 \mathrm{~kg} / \mathrm{m}^{3}$. For the measurement, we can distinguish the loose or tapped bulk density.

The loose bulk density is given according to standard EN 1236 [7]. The procedure and the equipment are relatively simple. Fertilizer flows from a funnel in a cylinder (approximately 11 ) by letting it overflow. The surplus is removed using a spatula being careful to avoid vibrations and then weighs the mass of the content of the cylinder.

The loose bulk density is equal to:

$\frac{m}{V}$

where:

- $\quad V$ is volume in $\mathrm{m}^{3}$ of the graduated cylinder,

- $m$ is the mass of fertilizer in the cylinder in $\mathrm{kg}$.

The standard EN 1237 [8] is followed for the measurement of the tapped bulk density. The cylinder is placed on a device, which consists of a simple cam turning with con-

Table 1

Physical properties of the fertilizers used for our bulk blends

\begin{tabular}{|c|c|c|c|c|c|c|c|c|c|c|c|}
\hline Blend & Chem & $d_{16}(\mathrm{~mm})$ & $d_{50}(\mathrm{~mm})$ & $d_{84}(\mathrm{~mm})$ & GSI & $\alpha\left(^{\circ}\right)$ & $\rho\left(\mathrm{kg} / \mathrm{m}^{3}\right)$ & $\rho_{\mathrm{t}}\left(\mathrm{kg} / \mathrm{m}^{3}\right)$ & El & Rgh & $\mathrm{Rd}$ \\
\hline \multirow[t]{2}{*}{ P1 } & NPK & 2.57 & 2.86 & 3.15 & 10.08 & 33.88 & 964.21 & 1022.88 & 14.2 & 0.48 & 71.3 \\
\hline & NK & 2.55 & 2.87 & 3.28 & 12.81 & 32.88 & 994.71 & 1057.75 & 13.6 & 0.64 & 66.6 \\
\hline P2 & $\mathrm{K}$ & 1.62 & 2.65 & 4.20 & 48.66 & 38.66 & 1178.24 & 1257.47 & 27.1 & 2.94 & 40.2 \\
\hline \multirow[t]{2}{*}{ GL1 } & NP & 2.58 & 2.88 & 3.30 & 12.59 & 34.11 & 970.37 & 1019.98 & 14.0 & 0.50 & 70.5 \\
\hline & NK & 2.33 & 2.91 & 3.64 & 22.57 & 34.11 & 1011.73 & 1082.86 & 13.6 & 0.69 & 66.7 \\
\hline \multirow[t]{2}{*}{ GL2 } & $\mathrm{NP}$ & 2.95 & 3.42 & 3.88 & 13.68 & 36.71 & 905.35 & 960.03 & 20.9 & 0.40 & 76.4 \\
\hline & $\mathrm{N}$ & 2.58 & 3.29 & 4.19 & 24.56 & 36.50 & 867.45 & 918.52 & 21.9 & 0.53 & 74.6 \\
\hline \multirow[t]{2}{*}{ GM1 } & NPK & 2.93 & 3.49 & 4.03 & 15.77 & 32.75 & 1041.76 & 1091.54 & 12.7 & 0.41 & 70.4 \\
\hline & PK & 2.57 & 3.00 & 3.69 & 18.68 & 34.58 & 1099.83 & 1167.68 & 17.0 & 0.93 & 56.4 \\
\hline \multirow[t]{2}{*}{ GM2 } & NPK & 2.92 & 3.48 & 4.03 & 16.02 & 32.47 & 1061.57 & 1111.94 & 12.1 & 0.39 & 69.6 \\
\hline & NK & 2.52 & 2.91 & 3.56 & 17.91 & 32.66 & 1000.64 & 1070.16 & 13.9 & 0.72 & 65.8 \\
\hline \multirow[t]{2}{*}{ GM3 } & NPK & 2.92 & 3.48 & 4.03 & 15.94 & 33.10 & 1048.59 & 1102.85 & 12.3 & 0.45 & 67.5 \\
\hline & NP & 2.58 & 2.88 & 3.28 & 12.15 & 33.55 & 974.16 & 1032.52 & 13.9 & 0.67 & 66.9 \\
\hline \multirow[t]{2}{*}{ GM4 } & $\mathrm{P}$ & 2.93 & 3.41 & 3.89 & 14.19 & 34.73 & 1107.77 & 1134.11 & 20.4 & 0.26 & 79.5 \\
\hline & PK & 2.19 & 2.92 & 3.76 & 26.84 & 35.27 & 1138.51 & 1192.61 & 18.3 & 0.38 & 78.6 \\
\hline \multirow[t]{2}{*}{ GM5 } & K & 1.63 & 2.60 & 4.04 & 46.37 & 38.37 & 1176.8 & 1261.8 & & & \\
\hline & K & 2.22 & 3.11 & 4.08 & 29.86 & 37.36 & 1068.20 & 1144.12 & 26.6 & 1.91 & 49.2 \\
\hline \multirow[t]{2}{*}{ GH1 } & / & 3.25 & 3.78 & 4.55 & 17.17 & 35.42 & 1350.26 & 1395.02 & 17.7 & 0.14 & 84.0 \\
\hline & PK & 2.57 & 2.91 & 3.41 & 14.34 & 33.78 & 1209.14 & 1286.47 & 17.5 & 0.15 & 82.8 \\
\hline \multirow[t]{2}{*}{ GH2 } & PK & 3.27 & 4.21 & 5.20 & 22.92 & 33.19 & 1335.06 & 1399.55 & 14.3 & 0.26 & 75.9 \\
\hline & 1 & 2.41 & 2.90 & 3.65 & 21.41 & 34.34 & 1303.88 & 1378.04 & 17.2 & 0.61 & 67.0 \\
\hline \multirow[t]{2}{*}{ GH3 } & PK & 3.43 & 4.35 & 5.50 & 23.87 & 33.33 & 1339.77 & 1398.10 & 15.2 & 0.18 & 77.8 \\
\hline & 1 & 2.79 & 3.42 & 4.23 & 21.07 & 34.11 & 1280.80 & 1354.40 & 17.3 & 0.44 & 70.0 \\
\hline \multirow[t]{2}{*}{ MM1 } & PK & 2.84 & 3.49 & 4.14 & 18.68 & 35.07 & 1224.68 & 1295.07 & 17.3 & 0.63 & 65.7 \\
\hline & NPK & 2.91 & 3.46 & 4.01 & 15.87 & 32.88 & 1063.44 & 1104.50 & 12.5 & 0.36 & 71.4 \\
\hline \multirow[t]{2}{*}{ MM2 } & PK & 2.6 & 3.3 & 4.1 & 22.9 & 36.44 & 1084.2 & 1150.3 & & & \\
\hline & I & 2.80 & 3.43 & 4.25 & 21.07 & 34.39 & 1296.9 & 1360.1 & & & \\
\hline \multirow[t]{2}{*}{ MH1 } & $\mathrm{NP}$ & 2.67 & 3.17 & 3.82 & 18.17 & 35.87 & 910.40 & 967.52 & 18.9 & 0.83 & 64.1 \\
\hline & 1 & 2.77 & 3.38 & 4.15 & 20.44 & 34.20 & 1286.36 & 1354.15 & 16.6 & 0.34 & 72.7 \\
\hline \multirow[t]{2}{*}{ MH2 } & $\mathrm{N}$ & 2.82 & 3.47 & 4.17 & 19.43 & 37.30 & 855.03 & 915.87 & 22.5 & 0.52 & 73.8 \\
\hline & 1 & 2.75 & 3.34 & 4.03 & 19.12 & 35.67 & 1271.97 & 1355.40 & 19.8 & 0.30 & 79.1 \\
\hline \multirow[t]{2}{*}{ MH3 } & $\mathrm{N}$ & 2.64 & 3.16 & 3.99 & 21.47 & 35.82 & 869.39 & 928.34 & 21.5 & 1.13 & 59.7 \\
\hline & 1 & 2.34 & 2.88 & 3.58 & 21.44 & 34.06 & 1322.34 & 1399.83 & 18.1 & 0.77 & 64.4 \\
\hline \multirow[t]{2}{*}{ SM1 } & $\mathrm{N}$ & 2.96 & 3.49 & 3.95 & 14.21 & 30.88 & 1107.90 & 1161.85 & 12.0 & 0.18 & 76.5 \\
\hline & NPK & 2.80 & 3.34 & 3.89 & 16.29 & 33.28 & 1125.44 & 1187.93 & 14.6 & 0.60 & 67.8 \\
\hline \multirow[t]{2}{*}{ SM2 } & $\mathrm{N}$ & 2.54 & 3.30 & 3.91 & 20.85 & 31.01 & 1066.89 & 1112.58 & 10.0 & 0.15 & 79.3 \\
\hline & PK & 2.58 & 3.12 & 3.93 & 21.76 & 34.83 & 1097.16 & 1160.68 & 18.3 & 0.82 & 65.6 \\
\hline \multirow[t]{2}{*}{ SM3 } & $\mathrm{N}$ & 2.94 & 3.45 & 3.98 & 15.14 & 30.73 & 1109.3 & 1155.3 & & & \\
\hline & PK & 2.61 & 3.21 & 4.02 & 22.02 & 35.67 & 1078.34 & 1147.47 & 18.1 & 0.93 & 61.3 \\
\hline \multirow[t]{2}{*}{ SH1 } & $\mathrm{K}$ & 2.27 & 3.16 & 4.16 & 29.84 & 37.86 & 1062.82 & 1150.51 & 25.7 & 1.80 & 49.4 \\
\hline & $\mathrm{N}$ & 2.43 & 3.23 & 4.02 & 24.59 & 31.12 & 1036.30 & 1092.21 & 11.3 & 0.13 & 80.4 \\
\hline \multirow{2}{*}{$\mathrm{SH} 2$} & $\mathrm{~N}$ & 2.56 & 3.31 & 3.93 & 20.75 & 30.93 & 1050.76 & 1097.90 & 10.0 & 0.23 & 76.6 \\
\hline & K & 2.61 & 3.36 & 4.21 & 23.88 & 38.00 & 1065.01 & 1145.23 & & & \\
\hline
\end{tabular}

Chemical contents of the component (Chem), angle of repose $(\alpha)$, loose density $(\rho)$, tapped density $\left(\rho_{\mathrm{t}}\right)$, sieve mesh for the percentile $x \%\left(d_{x}\right)$, granulometric spread index (GSI), elongation (El), roughness (Rgh), roundness (Rd). 
Table 2

Bulk blends with components with difference of size

\begin{tabular}{|c|c|c|c|c|c|c|c|c|c|c|c|c|c|}
\hline \multirow[t]{2}{*}{ Difference $d_{50}$} & \multicolumn{3}{|c|}{ Fertilizer with low $d_{50}$} & \multicolumn{3}{|c|}{ Fertilizer with high $d_{50}$} & \multirow{2}{*}{$\begin{array}{l}\text { No } \\
\text { blend }\end{array}$} & \multicolumn{2}{|c|}{$\underline{\text { Difference } d_{50}}$} & \multicolumn{2}{|c|}{$\underline{\text { Difference GSI }}$} & \multirow{2}{*}{$\begin{array}{l}\text { Density } \\
\left(\mathrm{kg} / \mathrm{m}^{3}\right)\end{array}$} & \multirow{2}{*}{$\begin{array}{l}\text { Angle } \\
\left({ }^{\circ}\right)\end{array}$} \\
\hline & GSI & $d_{50}$ & GSI & GSI & $d_{50}$ & GSI & & Abs & $(\%)$ & Abs & $(\%)$ & & \\
\hline \multirow[t]{4}{*}{ Limited $(<10 \%)$} & 1 & 2.9 & 10.1 & 1 & 2.9 & 12.8 & $\mathrm{P} 1$ & 0.0 & 0.2 & 2.7 & 24 & 980 & 33.4 \\
\hline & 1 & 2.9 & 12.6 & $\mathrm{H}$ & 2.9 & 22.6 & GL1 & 0.0 & 0.9 & 10.0 & 57 & 990 & 34.1 \\
\hline & $\mathrm{H}$ & 3.3 & 24.6 & 1 & 3.4 & 13.7 & GL2 & 0.1 & 3.7 & 10.9 & 57 & 886 & 36.6 \\
\hline & $\mathrm{H}$ & 2.6 & 48.7 & $\mathrm{H}$ & 2.6 & 48.7 & $\mathrm{P} 2$ & 0.0 & 0.0 & 0.0 & 0 & 1180 & 38.7 \\
\hline \multirow{6}{*}{$\begin{array}{l}\text { Medium } \\
\qquad(>10 \% \text { and }<20 \%)\end{array}$} & 1 & 3.0 & 18.7 & 1 & 3.5 & 15.8 & GM1 & 0.5 & 15.3 & 2.9 & 17 & 1070 & 33.7 \\
\hline & & 2.9 & 17.9 & & 3.5 & 16.0 & GM2 & 0.6 & 17.7 & 1.9 & 11 & 1030 & 32.6 \\
\hline & & 2.9 & 12.2 & & 3.5 & 15.9 & GM3 & 0.6 & 18.8 & 3.8 & 27 & 1010 & 33.3 \\
\hline & 1 & & & $\mathrm{H}$ & & & & & & & & & \\
\hline & $\mathrm{H}$ & 2.9 & 26.8 & 1 & 3.4 & 14.2 & GM4 & 0.5 & 15.5 & 12.6 & 62 & 1120 & 35 \\
\hline & $\mathrm{H}$ & 2.6 & 46.4 & $\mathrm{H}$ & 3.1 & 29.9 & GM5 & 0.5 & 17.9 & 16.5 & 43 & 1122 & 37.9 \\
\hline \multirow[t]{5}{*}{ High $(>20 \%)$} & 1 & 2.9 & 14.3 & 1 & 3.8 & 17.2 & GH1 & 0.9 & 25.9 & 2.8 & 18 & 1280 & 34.6 \\
\hline & 1 & & & $\mathrm{H}$ & & & & & & & & & \\
\hline & $\mathrm{H}$ & & & 1 & & & & & & & & & \\
\hline & $\mathrm{H}$ & 2.9 & 21.4 & $\mathrm{H}$ & 4.2 & 22.9 & $\mathrm{GH} 2$ & 1.3 & 36.9 & 1.5 & 7 & 1320 & 33.8 \\
\hline & & 3.4 & 21.1 & & 4.3 & 23.9 & GH3 & 0.9 & 23.9 & 2.8 & 12 & 1310 & 33.7 \\
\hline
\end{tabular}

Low (1), High (H).

stant speed and a lifting height of $3.00 \mathrm{~mm}$. After vibration has been induced, the collar and the surplus are removed. The contents of the cylinder are then weighed. The density after packing is obtained by the formula:

$$
\frac{m}{V}
$$

where:

- $m$ is the mass of fertilizer $(\mathrm{kg})$,

- $\quad V$ is the volume of the cylinder $\left(\mathrm{m}^{3}\right)$.

The tapped bulk density is higher than the value of the loose density by about $40-80 \mathrm{~kg} / \mathrm{m}^{3}$.

\subsection{Description of the bulk blends}

For each mixture, $200 \mathrm{~kg}$ of each raw material was used. For the different studied criteria, at least six mixtures were carried out, including two with components presenting no differences on the physical level. The list with the physical properties of each component for all the tested blends is shown in Table 1.

For the particle size distribution analysis, it is necessary to take into account not only the diameter $d_{50}$ but also the granulometric range (Table 2). Selected conditions are:

- null variation, the differences of $d_{50}$ between the components are lower than $10 \%$ (approximately 0.3 $\mathrm{mm})=$ blends $G L$ or $P$,

- medium variation, differences ranging between $10 \%$ and $20 \%(0.3-0.7 \mathrm{~mm})=$ blends $G M$,

- high variation, differences higher than 20\% (approx. 0.7 $\mathrm{mm})=$ blends $G H$.

For each category of variation of $d_{50}$, a division is operated according to the value of granulometric dispersion (GSI). The values of GSI lower and higher than 20\% are defined as the reduced and high values respectively.

For the mixtures with components of different density, three categories were defined in the following way (Table 3):

- a null or reduced variation when the difference in loose bulk density between the components is lower than $10 \%$ (approximately $100 \mathrm{~kg} / \mathrm{m}^{3}$ ) = blends $P$,

- a medium variation, when this variation lies between $10 \%$ and $25 \%$ (between 100 and $250 \mathrm{~kg} / \mathrm{m}^{3}$ ) = blends $M M$,

- a high variation when it is higher than 25\% (approx. 250 $\mathrm{kg} / \mathrm{m}^{3}$ ) $=$ blends $M H$.

Table 3

Bulk blends with components with difference of density

\begin{tabular}{|c|c|c|c|c|c|c|c|c|c|c|}
\hline \multirow[t]{2}{*}{ Density difference } & \multicolumn{2}{|c|}{ Density fertilizer «light» } & \multicolumn{2}{|c|}{ Density fertilizer «heavy» } & \multirow{2}{*}{$\begin{array}{l}\text { No } \\
\text { blend }\end{array}$} & \multicolumn{2}{|c|}{ Difference density } & \multirow{2}{*}{$\begin{array}{l}\text { Angle } \\
\left({ }^{\circ}\right)\end{array}$} & \multirow{2}{*}{$\begin{array}{l}d_{50} \\
(\mathrm{~mm})\end{array}$} & \multirow[t]{2}{*}{ GSI } \\
\hline & Loose & Tapped & $\overline{\text { Loose }}$ & Tapped & & $\overline{\mathrm{Abs}}$ & $(\%)$ & & & \\
\hline \multirow{2}{*}{ Limited $(<10 \%)$} & 1178 & 1257 & 1178 & 1257 & P2 & 0 & 0 & 38.7 & 2.6 & 48.7 \\
\hline & 964 & 1023 & 994 & 1058 & P1 & 30 & 3.1 & 33.4 & 2.9 & 11.4 \\
\hline \multirow[t]{2}{*}{ Medium $(>10 \%$ and $<25 \%)$} & 1063 & 1104 & 1225 & 1295 & MM1 & 161 & 14.1 & 34.0 & 3.5 & 17.4 \\
\hline & 1084 & 1150 & 1297 & 1360 & MM2 & 213 & 17.9 & 35.4 & 3.4 & 22.0 \\
\hline \multirow[t]{3}{*}{ High $(>25 \%)$} & 910 & 968 & 1286 & 1354 & MH1 & 376 & 34.2 & 35.0 & 3.3 & 19.0 \\
\hline & 855 & 916 & 1272 & 1355 & MH2 & 417 & 39.2 & 36.5 & 3.4 & 19.5 \\
\hline & 869 & 928 & 1322 & 1400 & MH3 & 453 & 41.3 & 34.9 & 3.0 & 30.1 \\
\hline
\end{tabular}


Table 4

Bulk blends with components with difference of shape

\begin{tabular}{|c|c|c|c|c|c|c|c|c|c|c|c|c|c|c|c|c|}
\hline \multirow[t]{2}{*}{ Shape difference } & \multicolumn{4}{|c|}{ Fertilizer «angulous» } & \multicolumn{4}{|c|}{ Fertilizer «spherical» } & \multirow{2}{*}{$\begin{array}{l}\text { No } \\
\text { blend }\end{array}$} & \multicolumn{4}{|c|}{ Shape difference $(\%)$} & \multirow{2}{*}{$\begin{array}{l}\text { Density } \\
\left(\mathrm{kg} / \mathrm{m}^{3}\right)\end{array}$} & \multirow{2}{*}{$\begin{array}{l}d_{50} \\
(\mathrm{~mm})\end{array}$} & \multirow[t]{2}{*}{ GSI } \\
\hline & Angle & $\mathrm{El}$ & $\mathrm{Rd}$ & $\overline{\mathrm{Rgh}}$ & Angle & $\mathrm{El}$ & $\mathrm{Rd}$ & $\overline{\text { Rgh }}$ & & Angle & $\mathrm{El}$ & $\mathrm{Rd}$ & Rgh & & & \\
\hline \multirow[t]{2}{*}{ Limited $(<5 \%)$} & 38.7 & 27.1 & 40.2 & 2.94 & 38.7 & 27.1 & 40.2 & 2.94 & P2 & 0.0 & 0 & 0 & 0 & 1178 & 2.6 & 48.7 \\
\hline & 33.9 & 14.2 & 71.3 & 0.48 & 32.9 & 13.6 & 66.6 & 0.64 & $\mathrm{P} 1$ & 3.0 & 4 & 7 & 29 & 980 & 2.9 & 11.4 \\
\hline \multirow[t]{3}{*}{ Medium $(5-15 \%)$} & 33.3 & 14.6 & 67.8 & 0.6 & 30.9 & 12.0 & 76.5 & 0.18 & SM1 & 7.5 & 20 & 12 & 108 & 1117 & 3.4 & 15.6 \\
\hline & 34.8 & 18.3 & 65.6 & 0.82 & 31.0 & 10.0 & 79.3 & 0.26 & SM2 & 11.6 & 59 & 19 & 137 & 1082 & 3.2 & 21.2 \\
\hline & 35.7 & 18.1 & 61.3 & 0.93 & 30.7 & 12.0 & 76.4 & 0.18 & SM3 & 14.9 & 40 & 22 & 135 & 1094 & 3.4 & 18.7 \\
\hline \multirow[t]{2}{*}{ High $(>15 \%)$} & 37.9 & 25.7 & 49.4 & 1.80 & 31.1 & 11.3 & 80.4 & 0.13 & SH1 & 19.5 & 78 & 48 & 173 & 1050 & 3.2 & 27.2 \\
\hline & 38.0 & 26.4 & 50.7 & 1.81 & 30.9 & 10.0 & 76.6 & 0.23 & $\mathrm{SH} 2$ & 20.5 & 90 & 41 & 155 & 1050 & 3.3 & 21.9 \\
\hline
\end{tabular}

Elongation (El), Roundness (Rd), Roughness (Rgh).

The average values for the properties of size and shape are common values for fertilizers.

For the mixtures whose components present a difference in shape, classification takes place on the basis of value of the static angle of repose (Table 4). Three categories are distinguished:

- null variation when the difference in angle of repose is lower than $5 \%$ (i.e., approximately $2^{\circ}$ ) $=$ blends $P$,

- medium variation when this difference varies between $5 \%$ and $15 \%$ (i.e., $2-5^{\circ}$ ) $=$ blends $S M$,

- high variation when this difference is higher than $15 \%$ (i.e., approximately $5^{\circ}$ ) $=$ blends $S H$.

It is noted that the magnitude of the variation of the angle of repose results proportionally from the difference observed for the three shape parameters determined by images analysis.

\subsection{Determination of the level of uncertainty related to our samples}

It is important to know the level of precision related to the chemical composition of certain samples since it will be used to determine the component proportions in the sample mixture. One can distinguish various samples taken during the experiment:

- raw material samples (sample of about $12 \mathrm{~kg}$ reduced to a minimum $300 \mathrm{~g}$ for chemical analysis).

- sample mixture from the emptying of the container $(3 \mathrm{~kg}$ reduced to minimum $300 \mathrm{~g}$ for chemical analysis).

The application of standard ISO 7553 [9] and of Gy's [10] formulas lead the $95 \%$ confidence interval mentioned in Table 5.

Table 5

Values of the confidence interval of the composition measurement (in \% of the value)

\begin{tabular}{lll}
\hline Samples & Gy $(\%)$ & ISO $(\%)$ \\
\hline Raw material & 1.9 & 2.2 \\
Emptying container & 2.9 & 4.2 \\
\hline
\end{tabular}

This calculated confidence interval is valid for various contents if the fertilizer contains several constituents. However, the uncertainty of analytical measurement must be added to the aforementioned sampling uncertainty. Total uncertainty is the quadratic average of uncertainties of each stage (sampling and measurement).

\section{Results}

The tests simulate flows such as those found in practice for the filling and the emptying of the trailer.

\subsection{Filling the trailer}

The fertilizer flows out of the mixer and forms a heap when filling the container. All tested mixtures show segregation of coarse particles at the periphery of the heap. A simple comparison of the median diameter $\left(d_{50}\right)$ of the samples (centre and edge of heap) shows an average difference of $0.15 \mathrm{~mm}$. The sample from the periphery is characterized by a higher $d_{50}$ value. On the other hand, the sample collected at the centre of the heap shows a content of fines (i.e., $<1.4 \mathrm{~mm}$ ) about $2.5 \%$, whereas it is 10 times less in the sample from the periphery.

A relation can be found between the variation of median diameter and the granulometric spread index $\left(d_{84}-d_{16}\right) /$ $\left(2 d_{50}\right)$ of the mixture (Fig. 1). The larger the range of the particle size distribution, the larger the variation of $d_{50}$ between the two samples.

The variations of shape or density do not appear to have accentuated or reduced the process of size segregation.

We observe that the result obtained for the blend having a GSI of 48 is unexpected. Actually, we don't have any explanation for this.

\subsection{Emptying the container}

The container is rocked backwards and emptied using a sliding trap. This system to empty a trailer is very commonly used in agriculture.

The segregation of size fractions is easy to observe. The central part of the trailer's contents comes out first, showing 


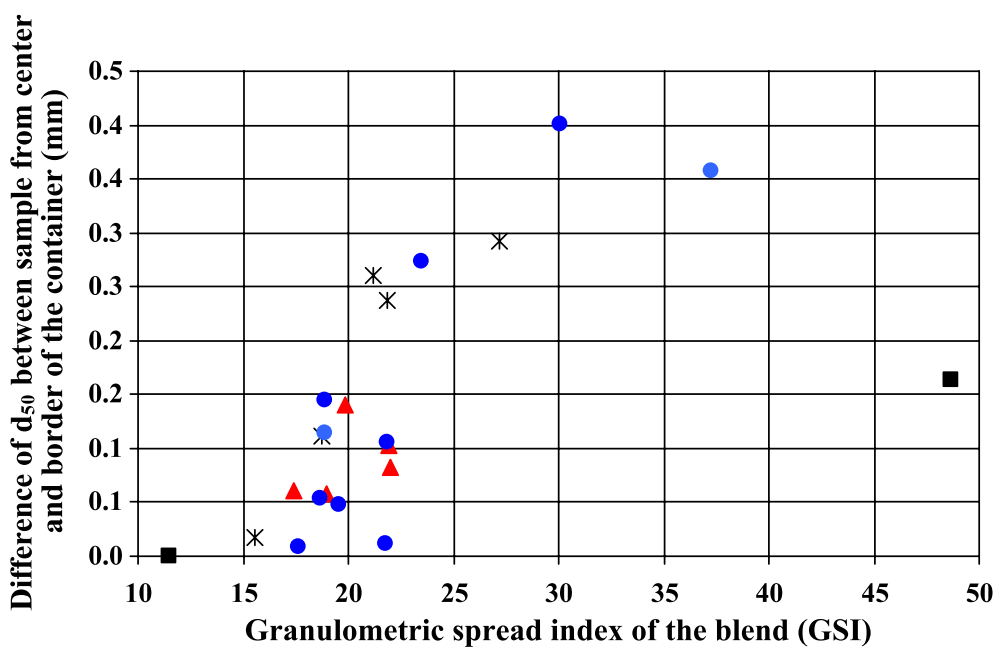

Fig. 1. Influence of the granulometric spread index on the granulometric segregation between the sample taken in the container. (Difference of the physical property of the components: $\boldsymbol{\bullet}=$ size; $\boldsymbol{\Delta}=$ density; ${ }^{*}=$ shape and $\boldsymbol{\square}=$ none).

mainly small particles, then the outer part comes afterwards showing mainly coarse fragments.

The comparison of the median diameters of the first and last (third) samples taken during the emptying of the container shows an average difference of about $0.4 \mathrm{~mm}$.

Similarly to what was observed for the samples taken in the trailer, the correlation between the size segregation during the emptying of the trailer and the granulometric spread index of the mixture is very good (Fig. 2). The difference in existing median diameter between the last and the first samples of emptying is highly correlated to the granulometric spread index of the mixture. For high values of this index, it is possible to measure variations of $d_{50}$ going up to $1 \mathrm{~mm}$. At the opposite, for blends having a GSI lower than 10, the granulometric segregation will negligible.

The samples taken during emptying were the subject of a chemical analysis. Knowing the chemical composition of the raw materials samples, it is possible to predict the proportion of each component in a sample from any mixture.

Indeed, if $M, A$ and $B$ are the contents of an element (N, $\mathrm{P}$ or $\mathrm{K}$ ) respectively of the sample of mixture and each raw material. There is a relation which binds these values:

$A \times P_{\mathrm{a}}+B \times P_{\mathrm{b}}=M$

With $P_{\mathrm{a}}$ and $P_{\mathrm{b}}$ being proportions of the raw materials respectively of contents $A$ and $B$, by knowing that $P_{\mathrm{a}}+P_{\mathrm{b}}$ equal $100 \%$.

Knowing $A, B$ and $M$ per chemical measurement, it is possible to calculate $P_{\mathrm{a}}$ and $P_{\mathrm{b}}$ easily, by the following relations

$P_{\mathrm{a}}=\frac{M-B}{A-B}$ and $P_{\mathrm{b}}=\frac{M-A}{B-A}$

This is realizable for each substantial quality of the bulk blend (nitrogen, phosphorus and potassium). The mixtures

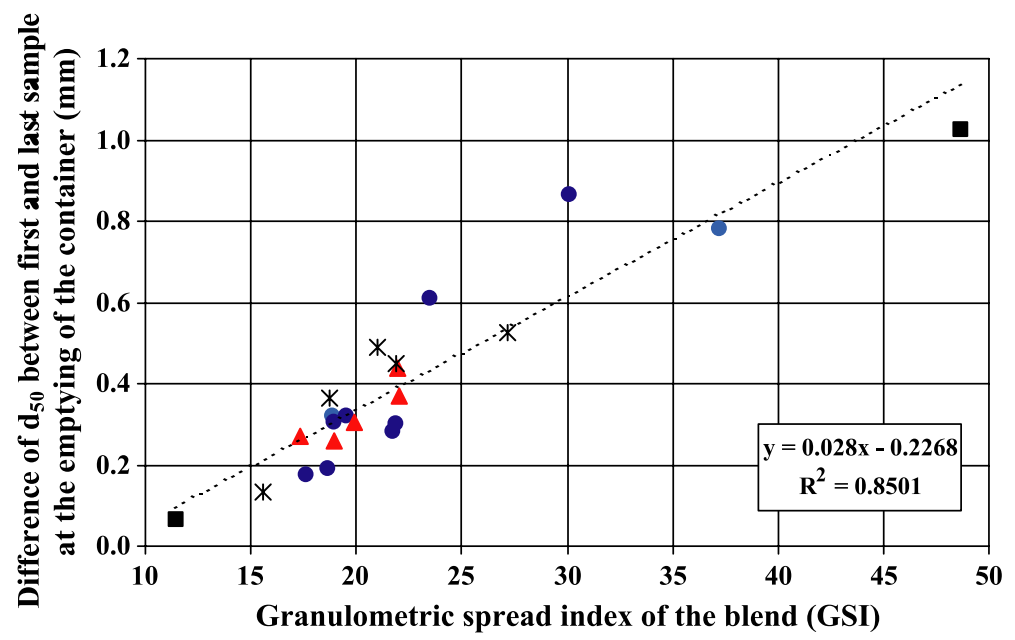

Fig. 2. Relation between the granulometric spread index of the bulk blend and the difference of $d_{50}$ for the first and third samples taken during the emptying of the container. (Difference of the physical property of the components: $\mathbf{O}=$ size; $\mathbf{\Delta}=$ density; $*=$ shape and $\boldsymbol{\square}=$ none). 
often having at least two elements, at least two values for $P_{\mathrm{a}}$ and $P_{\mathrm{b}}$ are obtained. The proportion values are not determined if the difference between the contents of the two components is lower than $50 \%$ of their average value and when this value is lower than 5 . In these situations, the imprecision due to the chemical analysis has too big influence on the calculated proportion.

The variance of the measured chemical composition of the raw materials and sample mixtures is the sum of the sampling variance and analytical variance.

Values obtained from raw materials and sample mixtures are used to calculate the proportion of each component in the sample mixture. The formula is a quotient in which the numerator and the denominator are not completely independent since the content of one of the components intervenes for each one of them. The formula of the variance of a quotient $N / D$ is the following one [11]:

$$
\begin{aligned}
\operatorname{Var}\left(\frac{N}{D}\right)= & \frac{1}{D^{2}} \times \operatorname{Var} N+\left(\frac{N}{D^{2}}\right)^{2} \\
& \times \operatorname{Var} D-\frac{2 \times N \times \operatorname{cov}(N, D)}{D^{3}}
\end{aligned}
$$

All the elements of this equation are known except covariance existing between the numerator and the denominator. By generating values (100) of chemical composition of known average and standard deviation according to a normal law for the compositions of the raw materials and sample mixture, it is possible to calculate the value of covariance between the numerator and the denominator. The values obtained vary from 0.03 to 0.2 . We will choose a value of 0.05 , in order not to give too much importance to the third term. This last reduces uncertainty since it is always negative.

Or if uncertainty $(U)$ is expressed:

$$
\begin{aligned}
& U\left(\frac{N}{D}\right) \\
& =2 \times \sqrt{\frac{1}{D^{2}} \times \operatorname{Var} N+\left(\frac{N}{D^{2}}\right)^{2} \times \operatorname{Var} D-\frac{2 \times N \times \operatorname{cov}(N, D)}{D^{3}}}
\end{aligned}
$$

or,

$$
U\left(\frac{N}{D}\right)=\sqrt{\frac{U_{N}^{2}}{D^{2}}+\left(\frac{N}{D^{2}}\right)^{2} \times U_{D}^{2}-\frac{8 \times N \times \operatorname{cov}(N, D)}{D^{3}}}
$$

The uncertainty of numerator $N$ and the denominator $D$ are simply the quadratic averages of uncertainties of the terms intervening in the two subtractions, the final formula thus becomes:

$$
U_{P_{\mathrm{a}}}=\sqrt{\frac{\left(\sqrt{U_{M}^{2}+U_{B}^{2}}\right)^{2}}{(A-B)^{2}}+\frac{(M-B)^{2}}{(A-B)^{4}} \times\left(\sqrt{U_{A}^{2}+U_{B}^{2}}\right)^{2}-8 \times \frac{(M-B)}{(A-B)^{3}} \times \operatorname{cov}(M-B, A-B)} .
$$

Normally, the values of $M$ and $B$ are not independent, the uncertainty of the numerator $N$ is lower than the quadratic average of the uncertainties of the terms $M$ and $B$. By this way, we sur-estimate the uncertainty of the determined proportion.

One proceeds the same way for the calculation of the proportion of the component $B$.

Here is an example of the determination of the uncertainty of the proportion of a fertilizer in a mixture sample. We consider that we mix a fertilizer $(A)$ containing $20 \%$ nitrogen with another fertilizer $(B)$ having no nitrogen. The chemical analysis of mixture sample $(M)$ indicates a $12 \%$ nitrogen content.

The theoretical proportion of fertilizer $A$ in the mixture sample is:

$P_{\mathrm{a}}=\frac{M-B}{A-B}=\frac{12-0}{20-0}=\frac{12}{20}=60 \%$

To calculate the uncertainty of this value we have to know the uncertainties of $M, A$ and $B$ which depend on:

- the uncertainty of the chemical analysis $\left(U_{1}\right)$ equal to $0.45 \%$ (given by the laboratory),
- the uncertainty of sampling given in Table 5 (we consider the ISO data).

For the mixture sample $(M)$, the uncertainty of the nitrogen content is:

$$
\begin{aligned}
U_{M} & =\sqrt{\left(\frac{M \times 4,2}{100}\right)^{2}+U_{1}^{2}}=\sqrt{\left(\frac{12 \times 4,2}{100}\right)^{2}+0.45^{2}} \\
& =0.67
\end{aligned}
$$

Thus, the nitrogen content of the mixture sample is $12 \pm 0.67$.

For $A$ and $B$, we respectively calculated the uncertainties of 0.63 and 0.45 .

Using the equation, we calculate the uncertainty of the proportion of fertilizer $A$ in the mixture sample which is about $4 \%$.

For several samples, the proportions are given on the basis of several contents (nitrogen, phosphorus or potassium). We thus determine an average proportion and an average uncertainty of this proportion. This value is obtained simply by the quadratic average of uncertainties 
related to each determination and divided by the number of analysed elements $(1,2$ or 3$)$. For each sample, we have determined the percentage of the components and the uncertainty of this value (Table 6).

It is noted that the granulometric segregation was sometimes accompanied by an important chemical segregation. Indeed, one and the other are not necessarily dependent. The first represents an accumulation of small or large particles at a precise place (edge or centre of a heap). If these particles come from each component or if they have similar composition, it does not necessarily lead to a significant difference in the chemical composition of the product. On the other hand, if most of small or large particles come from only one component, the granulometric segregation is accompanied by a chemical segregation.

Lastly, the difference between the two proportions in absolute value was determined (Table 7). The resulting uncertainty is the quadratic average of the uncertainties of the proportions. The boxes of the table with a coloured background indicate the samples for which the difference compared to the starting proportion (50\% of each matter) is higher than the uncertainty. It is observed that the chemical segregation takes place mainly in the last sample. Thirteen blends present a significant chemical segregation for the third sample with an average difference of $13.6 \%$, but only eight blends show segregation (average 5.1\%) for the first sample.

Correlation coefficients between the chemical segregation of the two components and their physical difference are calculated and summarized in Table 8. It is noted that the
Table 7

Difference of the proportion (fertilizer no. 1 and fertilizer no. 2) for the sample at the emptying of the container

\begin{tabular}{|c|c|c|c|c|}
\hline \multirow[t]{2}{*}{ No blend } & \multicolumn{2}{|l|}{ First sample } & \multicolumn{2}{|l|}{ Third sample } \\
\hline & Difference $(50 / 50)$ & Uncert. & Difference $(50 / 50)$ & Uncert. \\
\hline P1 & $3.3 \%$ & $4.2 \%$ & $7.0 \%$ & $4.3 \%$ \\
\hline \multicolumn{5}{|l|}{ P2 } \\
\hline GL1 & $5.1 \%$ & $4.3 \%$ & $2.6 \%$ & $4.3 \%$ \\
\hline GL2 & $2.9 \%$ & $4.2 \%$ & $8.0 \%$ & $3.9 \%$ \\
\hline GM1 & $5.7 \%$ & $7.0 \%$ & $31.4 \%$ & $7.5 \%$ \\
\hline \multicolumn{5}{|l|}{ GM2 } \\
\hline GM3 & $5.9 \%$ & $5.4 \%$ & $31.3 \%$ & $5.5 \%$ \\
\hline GM4 & $4.6 \%$ & $7.9 \%$ & $21.5 \%$ & $8.1 \%$ \\
\hline GM5 & $6.2 \%$ & $6.5 \%$ & $15.6 \%$ & $6.9 \%$ \\
\hline GH1 & $8.0 \%$ & $3.3 \%$ & $24.5 \%$ & $2.1 \%$ \\
\hline GH2 & $15.5 \%$ & $13.1 \%$ & $26.8 \%$ & $13.4 \%$ \\
\hline GH3 & $12.1 \%$ & $14.2 \%$ & $18.2 \%$ & $14.4 \%$ \\
\hline MM1 & $0.5 \%$ & $10.4 \%$ & $8.4 \%$ & $10.5 \%$ \\
\hline MM2 & $0.9 \%$ & $4.6 \%$ & $2.3 \%$ & $4.6 \%$ \\
\hline MH1 & $5.2 \%$ & $3.8 \%$ & $10.9 \%$ & $4.0 \%$ \\
\hline MH2 & $4.6 \%$ & $5.2 \%$ & $17.9 \%$ & $5.6 \%$ \\
\hline MH3 & $10.4 \%$ & $5.1 \%$ & $33.9 \%$ & $5.9 \%$ \\
\hline SM1 & $4.2 \%$ & $3.8 \%$ & $1.8 \%$ & $3.8 \%$ \\
\hline SM2 & $2.8 \%$ & $3.3 \%$ & $0.2 \%$ & $3.3 \%$ \\
\hline SM3 & $3.7 \%$ & $3.4 \%$ & $6.6 \%$ & $3.4 \%$ \\
\hline SH1 & $0.6 \%$ & $3.5 \%$ & $0.9 \%$ & $3.5 \%$ \\
\hline $\mathrm{SH} 2$ & $0.2 \%$ & $3.6 \%$ & $2.8 \%$ & $3.6 \%$ \\
\hline Average & $5.1 \%$ & & $13.6 \%$ & \\
\hline
\end{tabular}

difference in size of the components is the most important parameter in the segregation of the components but it does not explain everything.

Table 6

Proportion of each component for the first and third (last) sample taken during emptying of the container (proportion and uncertainty)

\begin{tabular}{|c|c|c|c|c|c|c|c|c|}
\hline \multirow[t]{3}{*}{ No blend } & \multicolumn{4}{|c|}{ First sample from emptying } & \multicolumn{4}{|c|}{ Third sample from emptying } \\
\hline & \multicolumn{2}{|l|}{ Fertilizer no. 1} & \multicolumn{2}{|l|}{ Fertilizer no. 2} & \multicolumn{2}{|l|}{ Fertilizer no. 1} & \multicolumn{2}{|l|}{ Fertilizer no. 2} \\
\hline & Proportion (\%) & Uncertainty (\%) & Proportion $(\%)$ & Uncertainty (\%) & Proportion (\%) & Uncertainty $(\%)$ & Proportion (\%) & Uncertainty (\%) \\
\hline $\mathrm{P} 1$ & 51.6 & 3.0 & 48.4 & 3.0 & 53.5 & 3.0 & 46.5 & 3.0 \\
\hline \multicolumn{9}{|l|}{ P2 } \\
\hline GL1 & 52.5 & 3.1 & 47.5 & 3.0 & 51.3 & 3.1 & 48.7 & 3.1 \\
\hline GL2 & 51.5 & 2.4 & 48.5 & 3.4 & 46.0 & 2.1 & 54.0 & 3.3 \\
\hline GM1 & 52.9 & 4.7 & 47.1 & 5.3 & 65.7 & 5.1 & 34.3 & 5.5 \\
\hline \multicolumn{9}{|l|}{ GM2 } \\
\hline GM3 & 47.0 & 3.8 & 53.0 & 3.8 & 65.7 & 4.1 & 34.3 & 3.6 \\
\hline GM4 & 47.7 & 5.4 & 52.3 & 5.8 & 60.7 & 5.6 & 39.3 & 5.8 \\
\hline GM5 & 53.1 & 5.1 & 46.9 & 4.0 & 42.2 & 5.2 & 57.8 & 4.5 \\
\hline GH1 & 46.0 & 2.8 & 54.0 & 1.7 & 62.3 & 2.4 & 37.7 & 1.6 \\
\hline $\mathrm{GH} 2$ & 42.3 & 8.8 & 57.7 & 9.7 & 63.4 & 9.7 & 36.6 & 9.3 \\
\hline GH3 & 43.9 & 9.6 & 56.1 & 10.4 & 59.1 & 10.3 & 40.9 & 10.1 \\
\hline MM1 & 50.2 & 7.6 & 49.8 & 7.1 & 45.8 & 7.5 & 54.2 & 7.3 \\
\hline MM2 & 50.4 & 2.9 & 49.6 & 3.5 & 51.1 & 2.9 & 48.9 & 3.5 \\
\hline MH1 & 47.4 & 2.3 & 52.6 & 3.0 & 55.4 & 2.5 & 44.6 & 3.1 \\
\hline MH2 & 47.7 & 3.2 & 52.3 & 4.1 & 59.0 & 3.6 & 41.0 & 4.3 \\
\hline MH3 & 44.8 & 3.1 & 55.2 & 4.1 & 66.9 & 3.9 & 33.1 & 4.4 \\
\hline SM1 & 47.9 & 2.7 & 52.1 & 2.7 & 50.9 & 2.7 & 49.1 & 2.7 \\
\hline SM2 & 51.4 & 2.4 & 48.6 & 2.3 & 49.9 & 2.4 & 50.1 & 2.3 \\
\hline SM3 & 48.1 & 2.5 & 51.9 & 2.3 & 46.7 & 2.5 & 53.3 & 2.3 \\
\hline SH1 & 50.3 & 2.5 & 49.7 & 2.5 & 50.5 & 2.5 & 49.5 & 2.5 \\
\hline $\mathrm{SH} 2$ & 50.1 & 2.5 & 49.9 & 2.5 & 48.6 & 2.5 & 51.4 & 2.6 \\
\hline
\end{tabular}


Table 8

Correlation $(R)$ between the observed segregation of the components for the sample at the emptying of the container and the difference of component properties

\begin{tabular}{llllllr}
\hline Difference of physical property & & & & & \\
\hline & & $d_{16}$ & $d_{50}$ & $d_{84}$ & Density & Angle \\
\hline Diff (sample no1) & $\mathrm{R}$ & 0.561 & 0.697 & 0.583 & 0.087 & -0.474 \\
& Prob. & 0.007 & 0.000 & 0.004 & 0.699 & 0.026 \\
Diff (sample no3) & $\mathrm{R}$ & 0.472 & 0.534 & 0.424 & 0.341 & -0.380 \\
& Prob. & 0.026 & 0.010 & 0.049 & 0.121 & 0.081 \\
\hline
\end{tabular}

The first sample containing a higher proportion of fine particles contrary to the last which sees its proportion of large granules observed, it can be judicious to express the variation between granulometry of the raw materials by the sum, in absolute value, of the difference between the $d_{16}$ of each matter with the difference between the $d_{84}$ of these same materials. The computing formula is:

Absolute value of $\left(d_{16 \text { mat } 1}-d_{16 \text { mat2 } 2}\right)+\left(d_{84 \text { mat1 }}-d_{84 \text { mat2 } 2}\right)$

The relation between the values thus calculated and the degree of segregation does not reveal any tendency for the first sample. On the other hand, for the last sample where the maximum variation is observed, the greater the difference in contents, the more the segregation between the two components is observed (Fig. 3). It appears that the segregation increases rather quickly and reaches a maximum of about $30 \%$, which corresponds to a proportion of the components of $35 / 65$. This level is reached when the variation between the components exceeds $1 \mathrm{~mm}$. In order to limit the chemical segregation, the absolute sum of the differences of $d_{16}$ and $d_{84}$ must not exceed $0.5 \mathrm{~mm}$.

\section{Conclusions}

The tests confirm the existence of a granulometric segregation during the flows of fertilizers. The simple fact of filling a trailer causes a segregation which is marked by an accumulation of the fine particles in the centre of the heap, while the largest particles concentrate in periphery.

This process can be avoided if the granulometric spread index (GSI) of the bulk blend is lower than 15. At the contrary, values of GSI higher than 25 are characterized by excessive size segregation of the particles.

The second stage which consists in emptying the trailer by a trap door is at the origin of an even greater, observed segregation. For some mixtures, the differences which appear between the product coming from the beginning and the end of emptying of the trailer are so great that they can be visually observed. The size of the particles of the fertilizer varies during emptying and the behaviour of the blend will be influenced during the following operations such as spreading on the field. Thus, it is necessary to limit this process of granulometric segregation. A relation is found between the GSI and the granulometric segregation. According to the relation underlined, the mixture must have a GSI of about 10 to present no risk of segregation.

The segregation can be accompanied by a chemical composition heterogeneity. An initial mixture of 50\% for each component can lead to segregated mixture between $35 \%$ and $65 \%$ after flows take place. In order to limit this phenomenon the absolute sum of the differences of $d_{16}$ and $d_{84}$ of each matter must be limited to approximately $0.5 \mathrm{~mm}$.

It seems that the difference in density tends to increase the chemical segregation of the particles during the flows if the lighter fertilizers also have the biggest particles. The



Fig. 3. Evolution of the component segregation of the blend for the third sample at the emptying of the container in function of the difference of granulometry of the components. (Difference of the physical property of the components: $\boldsymbol{\theta}=$ size; $\boldsymbol{\Delta}=$ density; ${ }^{*}=$ shape and $\boldsymbol{\square}=$ none). 
granulometric segregation is not amplified but results in a more important chemical segregation for differences in bulk density of $40 \%$.

\section{References}

[1] O. Miserque, Etude des caractéristiques physiques des particules limitant l'homogénéité des mélanges d'engrais, Rapport Fonds des Matières premières et des Produits transformés, Ministère des Classes Moyennes et de l'Agriculture, Belgique, 1998, $65 \mathrm{pp}$.

[2] NORME EN 1482 Engrais solides-Echantillonnage des matières fertilisantes solides et des amendements calciques et/ou magnésiens. Norme européenne, avril 1996.

[3] NORME EN 1235 Engrais solides-Tamisage de contrôle (ISO 8397: 1988 modifiée). Norme européenne, juin 1995.

[4] E. Pirard, Shape processing and analysis using the calypter, Journal of Microscopy 175 (Pt 3) (1994) (214-221 pp.).

[5] NORME EN 12047 Engrais solides-Mesurage de l'angle de talus d'éboulement (ISO 8398: 1989 modifiée). Norme européenne, septembre 1996

[6] O. Miserque, E. Pirard, S. Tissot, Caractérisation des particules d'engrais: corrélation entre les propriétés physiques et morphométriques, Visualisation-Image-Modélisation 15 (Nancy).

[7] NORME EN 1236 Engrais-Détermination de la masse volumique sans tassement (ISO 3944: 1992 modifiée). Norme européenne, juin 1995.

[8] NORME EN 1237 Engrais-Détermination de la masse volumique après tassement (ISO 5311: 1992 modifiée). Norme européenne, juin 1995.

[9] ISO (1987). Rapport technique 7553. Engrais-Echantillonnage-Masse minimale de prélèvement en cas de traitement de la totalité de l'unité d'échantillonnage à prélever. Organisation Internationale de Normalisation, Genève, Suisse, 7 pp.

[10] GY P. L'échantillonnage des minerais en vrac. Tome 1 Mémoires du Bureau de Recherches géologiques et minières no 56. Ed. BRGM 1967, $188 \mathrm{pp}$.

[11] Norme AFNOR FD V03-116-Analyse des produits agricoles.Guide d'application des données métrologiques, juin 2001 